\title{
IMPACT OF TOPICAL INSULIN ON ORAL MUCOSAL WOUND HEALING IN DIABETIC AND NON DIABETIC RATS
}

\author{
Soha Basha*
}

\begin{abstract}
Diabetes mellitus is a chronic, lifelong metabolic disorder. Impaired wound healing capabilities in both cutaneous and oral ulceration was denoted among diabetic patients. Topical treatments include natural therapeutic products as oxidized regenerated cellulose/collagen, hyaluronic acid conjugated with glycidyl methacrylate or gelatin dressings and insulin. Different studies have proved the efficacy of topical insulin on skin ulcers. The aim of the present study was to evaluate the effectiveness of topical insulin on oral ulcers in diabetic and non-diabetic rats through histological examinations.
\end{abstract}

Material and methods: 48 male albino rats were used in this study, rat population was divided into diabetic and non-diabetic groups. Each group was subdivided into test subgroup treated by insulin and control subgroup treated by placebo. Histological examination was performed to rats sacrificed after 2, 7 and 14 days.

Results: Better healing was observed in nondiabetic groups compared to diabetic groups. Improved healing was noticed in groups treated by insulin manifested by hyperplastic orthokeratinized epithelium with prominent granular cell layer, while ulceration was still denoted in the groups treated by plecebo.

Conclusion: From the present study, it was concluded that topical insulin can be considered as a safe and effective treatment modality for oral ulcers.

KEYWORDS: diabetic, histological, insulin, placebo, topical, ulcer.

\section{INTRODUCTION}

Diabetes mellitus is a chronic, lifelong metabolic disorder. It is a worldwide health problem caused by inherited or acquired deficiency in insulin production by the pancreas or by the ineffectiveness of the insulin, which result in hyperglycemia.
Symptoms of marked hyperglycemia include polyuria, polydipsia, weight loss, polyphagia, blurred vision, high susceptibility to infections and impaired wound healing. ${ }^{1}$ Wound healing is an important biological process influenced by several agents such as insulin-like growth factor (IGF) and human acidic fibroblast growth factor (rh-aFGF). ${ }^{2,3}$

* Oral medicine, Periodontology and Radiology Department, Faculty of Dentistry/ Pharos University in Alexandria, Egypt. 
Several studies in both medical and dental literatures reported that the oral cavity is among the affected organ that is extensively affected by diabetes. Significant changes are observed in oral microflora, salivary glands and periodontium. High prevalence of irritation fibromas and persistent oral ulcers were also reported. ${ }^{4}$

Impaired wound healing capabilities in both cutaneous and oral ulceration among diabetic patients is the main concern for many researches. They reported that delayed wound healing attributed to various underlying mechanisms includes decreased growth factor production, angiogenic response, macrophage function, collagen accumulation, epidermal barrier function, keratinocyte and fibroblast migration and proliferation 5,6,7. Additionally, Diabetic patients are under state of immunosuppression. Accumulation of advanced glycation end products (AGE) causes decrease in number of migrated neutrophils at the site of inflammation. ${ }^{8}$

Treatment of chronic skin ulcers in diabetic and non-diabetic patients was one of the main issues that concerns researchers throughout the world and there has been several treatment modalities introduced by the specialists in order to treat these nonhealing wounds..$^{9,10}$ The treatment modalities divided into systemic or topical treatments. However, for its fewer side effects the topical treatment is mostly used. Topical treatments include natural therapeutic products as well as topical therapeutic methods such as topical application of growth factors, oxidized regenerated cellulose/collagen, hyaluronic acid conjugated with glycidyl methacrylate or gelatin dressings and insulin. ${ }^{2}$

In addition, for treatment of chronic oral ulcers advanced expertise in different topical medication were introduced as antiseptics (chlorhexidine) ${ }^{11}$, anti-inflammatory drugs (amlexanox ${ }^{12}$ ), antibiotics (tetracyclines) $)^{13}$ and corticosteroids (prednisone) $)^{14}$ and immune-modulators (pentoxifylline).$^{15}$

The purpose of this study was to introduce and add to the field of oral ulcers treatment using topical medications a new innovation, which is topical insulin, and to evaluate its effectiveness on oral ulcers in diabetic and non-diabetic rats through histological examinations.

\section{MATERIAL AND METHODS}

48 Male Albino rats weighing 200-250 gm were used in this study. The animals were kept at the animal house of Faculty of Dentistry, Pharos University in polypropylene cages. All rats were fed with standard laboratory pellets and tap water ad libitum throughout the study period. The room temperature was about $22-24^{\circ} \mathrm{C}$ and the animals were exposed to 12:12 hours light dark cycles. The present research protocol was approved by the Ethics Review Board of Faculty of Dentistry, Pharos University.

\section{Diabetes induction:}

Diabetes mellitus was induced to 24 rats by intravenous injection of $42 \mathrm{mg} / \mathrm{kg}$ of alloxan monohydrate (Sigma Chemical Co., St. Louis, MO, USA) dissolved in physiologic saline after an overnight fasting period. ${ }^{16}$ The presence of diabetes was proved by blood glucose concentrations ( $>11.2$ $\mathrm{mmol} / \mathrm{l}$ ) determined by glucometer (One Touch, Ultra, Lifescan, America). A blood glucose level $>200 \mathrm{mg} / \mathrm{dL}$ was indicative of diabetes. ${ }^{17}$

\section{Ulcer induction:}

Oral ulcers were induced in all rat population. Rats were fixed on their backs and all animals were anesthetized with an intra-peritoneal injection of ketamine (pharmazeutische proparate, Pfaffen-Schwabenheim, Germany) and xylazine (Chanazine, Chanelle pharmaceutical manufacturing Ltd., Loughrea, Co. Galway, Ireland.) (90 and $15 \mathrm{mg} / \mathrm{kg}$, respectively), Round filter papers $5.5 \mathrm{~mm}$ in diameter were soaked in $15 \mathrm{ml}$ of $50 \%$ acetic acid was applied over the upper labial gingiva for $60 \mathrm{sec}-$ onds to create round uniform ulcer. ${ }^{18}$

\section{Study groups:}

The rat population was divided into two main groups, each group divided into two subgroups (test and control groups), 12 rats each: 


\section{Diabetic group: 24 rats subdivided into:}

- Diabetic rats treated by insulin (test group)

- Diabetic rats treated by placebo (control group):

\section{Non- Diabetic group: 24 rats subdivided into:}

- Diabetic rats treated by insulin (test gp):

- Diabetic rats treated by placebo (control gp):

To evaluate the safety of topical Insulin, random blood glucose levels were noted 15 minutes before and after insulin application in test groups of diabetic and non diabetic rats.

\section{Topical insulin preparation:}

Melt $30 \mathrm{~g}$ white soft paraffin and stir until cold. Add 3 mL (300 IU) of insulin (Humulin 70/30) with a portion of the base and gradually incorporate the remainder of the base. The insulin concentration in the resultant ointment is $10 \mathrm{IU}$ per gram. This cream was applied twice daily with a cotton-tipped applicator for diabetic and nondiabetic test groups.

\section{Topical placebo preparation}

Melt $30 \mathrm{~g}$ white soft paraffin and stir until cold. This base was applied with a cotton-tipped applicator twice daily for diabetic and nondiabetic control groups.

Topical insulin and placebo were kept in a refrigerator until used for the purpose of the study.

\section{Animal sacrifice:}

Four rats from each group were sacrificed at day $2,7,14$ by an overdose intra-peritoneal injection of $100 \mathrm{mg} / \mathrm{kg}$ Phenobarbital sodium (West Ward Pharm., USA). Each wound was excised, maintaining approximately $3 \mathrm{~mm}$ of mucosa around the incision.

\section{Histological Evaluation:}

The excised tissues were fixed with $10 \%$ formalin. Specimens of labial mucosa were obtained and fixed in $10 \%$ neutral formalin for 48 hours.
Then they were dehydrated in ascending grades of alcohol and embedded in paraffin. Histological sections of $5 \mu \mathrm{m}$ thickness were obtained and stained with hematoxylin and eosin stain according to the conventional method. ${ }^{19}$ Then the specimens were prepared for histological examination

\section{RESULTS}

Blood glucose level was measured in diabetic and non diabetic rats. The blood glucose level in diabetic group at baseline was ranging from (230$250 \mathrm{mg} / \mathrm{dl}$ ) and for the non diabetic was ranging from (85-95mg/dl). No changes occurred in the detected levels before or after treatment Topical insulin did not induce changes in the blood glucose levels of control or diabetic animals.

Regarding the nondiabetic rat ulcers treated with insulin, atrophic epithelium with mild inflammatory cell reaction in the lamina propria after 2 days was noticed. After 7 days hyperplastic parakeratinized epithelium with long rete ridges was found. Finally after 14 days hyperplastic orthokeratinized epithelium with prominent granular cell layer and bulbous rete ridges were observed (Fig. 1). On the other hand, the nondiabetic rats treated with placebo showed single layer of basal epithelial cells after 2 days, while ulcerative non-keratinized epithelium was denoted after 7 days. After 14 days atrophic non-keratinized epithelium with short rete ridges was detected (Fig. 2).

Concerning, the diabetic group treated with insulin, ulcerative atrophic non-keratinized epithelium was seen after 2 and 7 days. While, after 14 days hyperplastic parakeratinized epithelium with long rete ridges was seen (Fig. 3). However, the diabetic group treated with placebo ulcerative surface epithelium with massive inflammatory cell reaction and increased vascularity was denoted after 2 days, these ulcerative non-keratinized surface epithelium was still present after 7 and 14 days. 


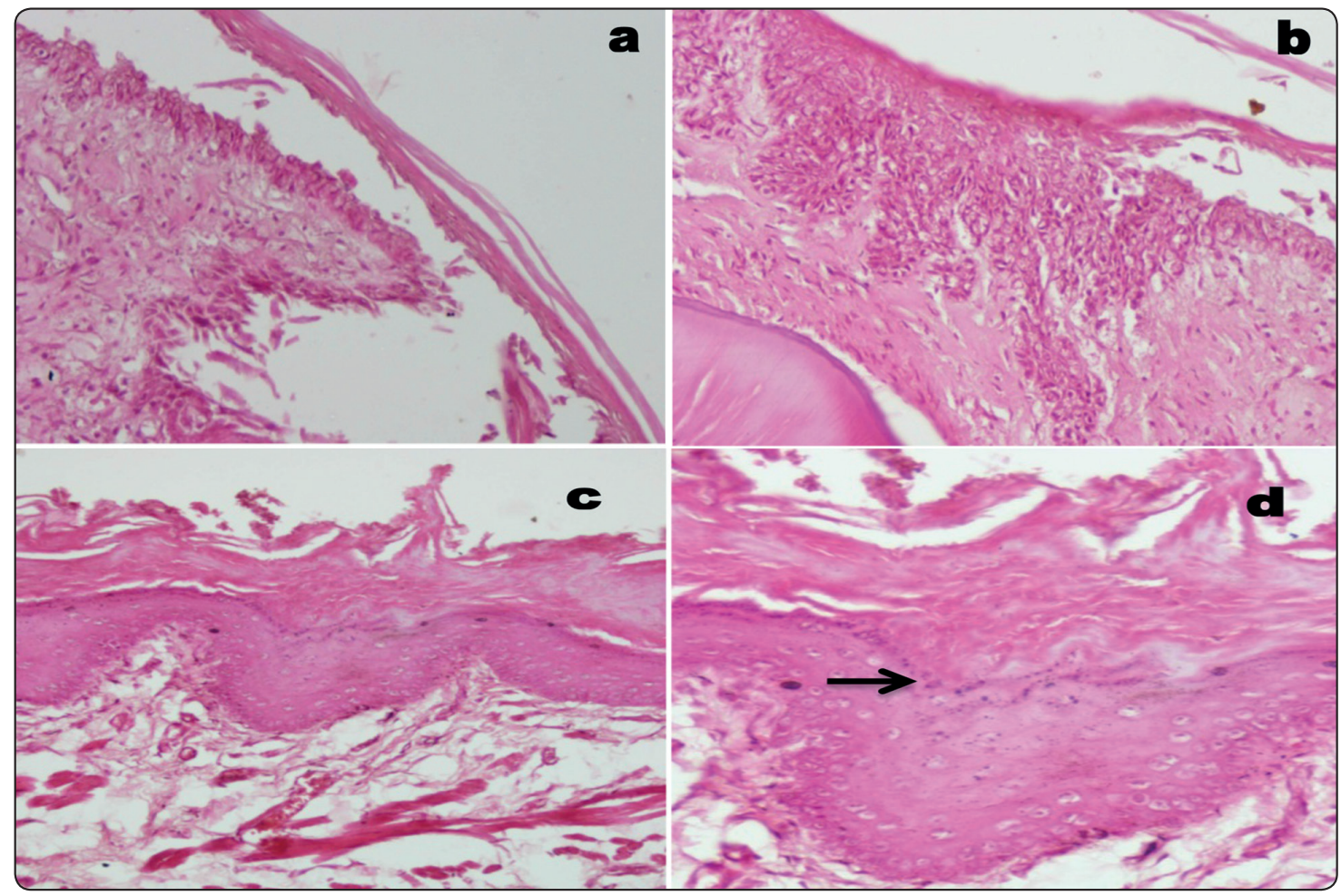

Fig. (1) A photomicrograph of sequential histological changes of healing process in group 1 (ulcers in non-diabetic rates treated with topical insulin). a: after 2 days showing atrophic epithelium with mild inflammatory cell reaction in the lamina propria, b: after 7 days showing hyperplastic parakeratinized epithelium with long rete ridges, c and d: after 14 days showing hyperplastic orthokeratinized epithelium with prominent granular cell layer (black arrow) and bulbous rete ridges. (a-d: H\&E, a-c x200, d x400)

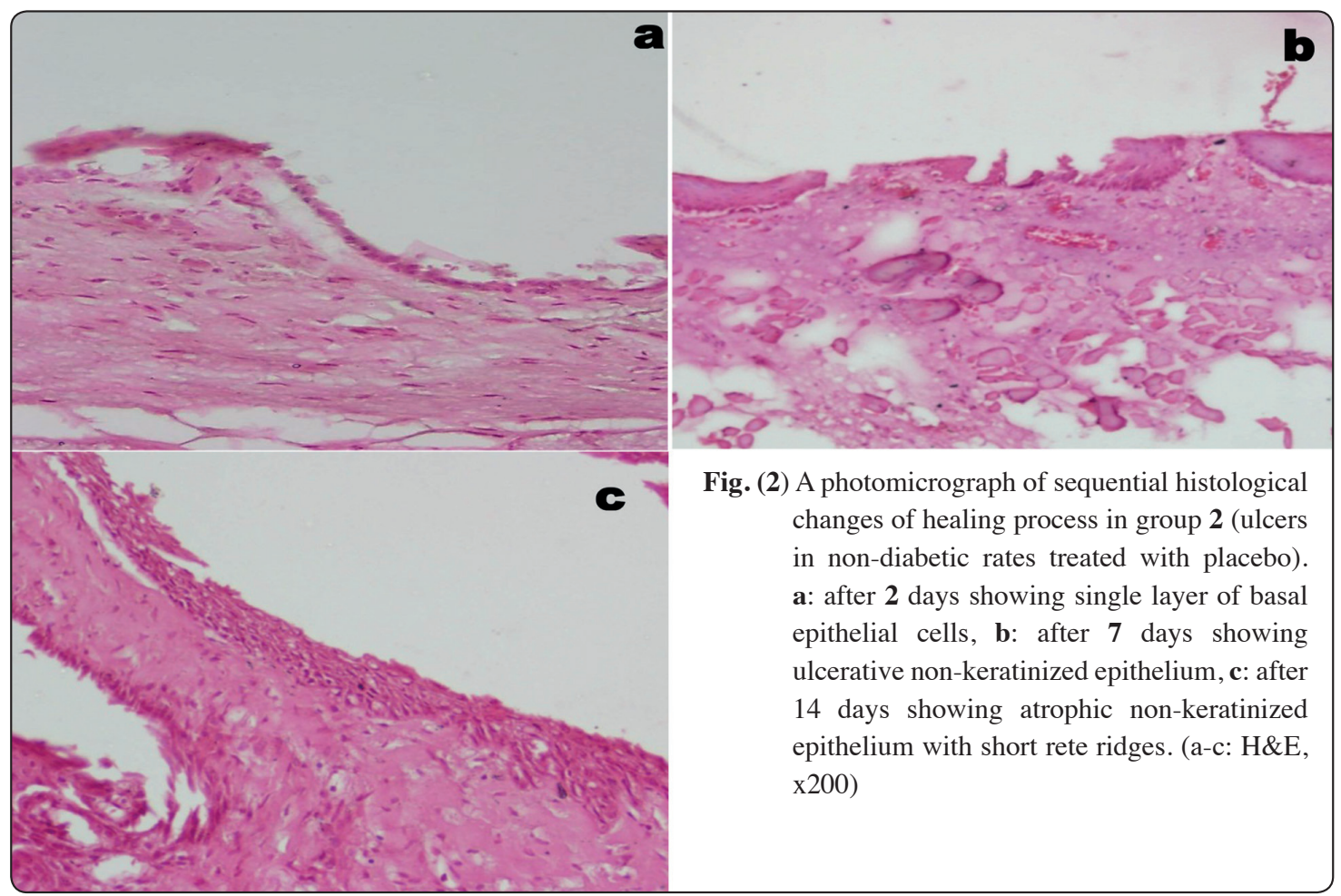



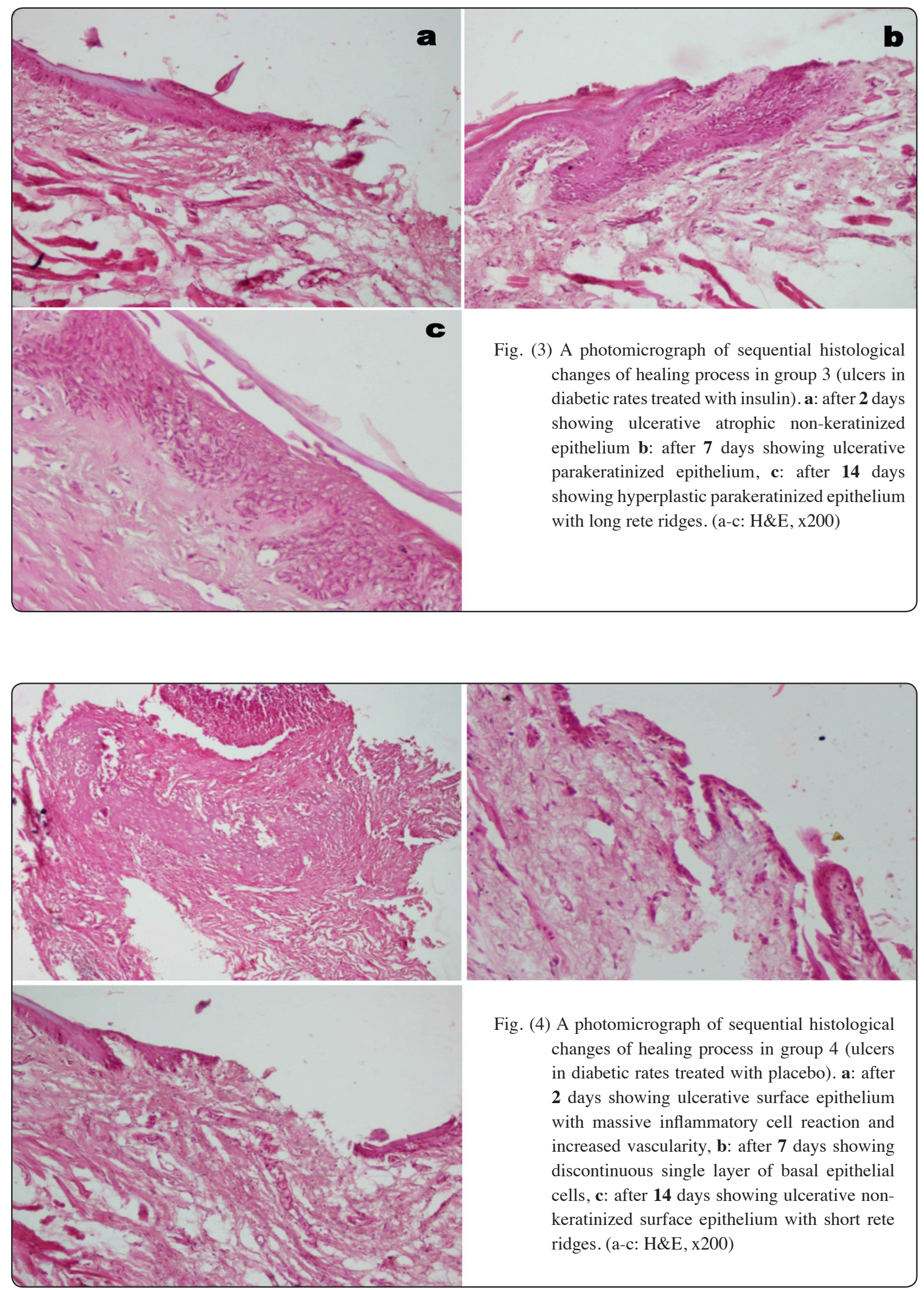


\section{DISCUSSION}

Insulin is a poly peptide hormone which was widely investigated for its numerous uses and benefits including stimulating collagen synthesis in skin fibroblasts and activate myofibroblasts production..$^{20}$ Moreover, insulin reduces the bacterial survival environment, enhances the ability of local inflammation and thus promotes local wound healing. ${ }^{21}$ Correspondingly, the effect of topical insulin on oral ulcers in diabetic and nondiabetic albino rats was investigated. In the present study we confirmed that topical insulin has no effect on blood glucose level. This is in accordance with Geonka et al. ${ }^{2}$ who reported that topical Insulin is not absorbed systemically and didn't cause decrease in blood glucose level.

Several clinical and experimental studies over many decades ${ }^{2,20,22,23}$ have evaluated the effect of topical insulin in healing of skin ulcers and they concluded that topical insulin application accelerate cutaneous wound healing.

In the present study, there was an obvious histological improvement for insulin group compared to control group, this mean that the healing is better among insulin group than control group.

Regarding healing of the two nondiabetic groups, the group treated with insulin showed apparently normal epithelium manifested by heperplastic parakeratinized epithelium with long rete ridges after 7 days while the group treated by placebo still showed ulcerative non keratinized epithelium. Moreover, after 14 days the group treated by insulin showed complete healing manifested by hyperplastic orthokeratinized epithelium with prominent granular cell layer and bulbous rete ridges while, the group treated by placebo showed incomplete healing manifested by atrophic non-keratinized epithelium with short rete ridges. This result goes in line with El-said et al, ${ }^{24}$ they concluded that using topical insulin was effective and safe method to accelerate healing in nondiabetic cases.
In the current study, nondiabetic group showed outstanding results regarding the factor of time. In which the time taken for complete epithelialization was the least. In support for these results, Apikoglu et al. ${ }^{25}$ also stated in his experiments that, administration of topical insulin enhanced wound healing by shortening the time needed for complete epithelialization in the nondiabetic group. Furthermore, he also added that the histological result showed an increased number of collagen fibers in the topical insulin-treated rats. Similarly, Azevedo' et al ${ }^{26}$ results also suggested that topical insulin had beneficial effect on tissue formation in second-degree burns and is attributable to enhanced proliferation of fibroblasts, causing an increase in the deposition and organization of collagen fibers. For further elaboration, he added that some of these fibroblasts differentiate into myofibroblasts, which are involved in wound contraction.

Concerning the diabetic group healing in both sub groups was retarded compared to the nondiabetic group. This was attributed to the effect of diabetes on healing. Paraveen et al ${ }^{27}$ reported that there are several factors that have the potential to contribute to a delay in wound healing in diabetic patients, including poorly controlled blood glucose levels, poor tissue oxygenation and impaired immune response to injury. In the present study, after 7 days ulcerative non parakeratinized epithelium was denoted in the group treated with insulin while discontinuous single layer of basal epithelial cells was noticed in the placebo group. Comparing insulin and placebo diabetic groups after 14 days, better healing was realized in the insulin group manifested by hyperplastic parakeratinized epithelium with long rete ridges while in the placebo group still ulcerative non-keratinized surface epithelium with short rete ridges.

Several authors in recent clinical and experimental studies has been attempted to explain the mechanisms of action of topical insulin in wound healing. Shanley et al. ${ }^{28}$ concluded that the insulin is a peptide closely related to insulin-like growth factor (IGF) that is able to stimulate haptotactic migration of human epidermal keratinocytes and 
is implicated in wound repair. In 2017, Seng Fai 29 experiments reassured and supported the previously mentioned results of IGF on accelerating the wound healing of the corneal epithelium.

Liu, et al. ${ }^{3}$ showed that insulin interacts with its receptor and affects multiple aspects of keratinocyte behavior, including stimulation of cell motility, increased expression of the cell surface adhesion molecule integrin $\alpha 3$ and enhanced secretion of the extracellular matrix (ECM) molecule laminin 332 (LN332) resulting in an integrated effect in the epithelium and the underlying granulation tissue. Furthermore, it was shown that human keratinocytes are dependent on insulin for their growth. ${ }^{30}$

Another mechanism was explained by Chin et al. ${ }^{31}$ the authors concluded that topical insulin application decreased neutrophil infiltration by inhibiting macrophage inflammatory protein 2 (MIP-2) expression and advanced neutrophil resolution. A study was made in favor of insulin and its powerful effect on regulating the wound inflammatory response. It showed that the insulin specifically elevates the quantity of macrophages infiltration by regulating wound Monocyte chemoattractant protein-1 (MCP-1) expression. Thus increasing the functions of macrophages including chemotaxis, Pinocytosis/phagocytosis and secretion of inflammatory mediators regulating wound inflammatory response. Hence, these results explain how insulin is a potent healing accelerant. ${ }^{32}$

Consequently, topical insulin can be considered as an effective accelerator in oral ulcer healing. It is found to be safe and effective without any systemic side effects. . $^{33,34,35,36}$

\section{CONCLUSION}

Topical insulin has no effect on blood glucose level and thus, can be used with nondiabetic cases. The present study demonstrated that topical insulin promotes the healing of ulcers in both diabetic and non-diabetic rats. Accordingly, the author recommends the utilization of topical insulin due to its availability, safety and advantageous effects.

\section{REFERENCES}

1. Vasconcelos BC, Novaes M, Sandrini FA, Maranhão Filho AW, Coimbra LS. Prevalence of oral mucosa lesions in diabetic patients: a preliminary study. Braz J Otorhinolaryngol. 2008; 74(3):423-8.

2. Goenka G, Athavale VS, Nirhale DS, Deshpande N, Agrawal K, Calcuttawala M. Role of topical use of insulin in healing of chronic ulcer. Med J DY Patil Univ 2014;7:579-83.

3. Liu Y, Petreaca M, Yao M, Martins-Green M. Cell and molecular mechanisms of keratinocyte function stimulated by insulin during wound healing. BMC Cell Biol 2009;10:1186-1190.

4. Sanjeeta N. Oral changes in Diabetes - a review. IOSRJDMS. 2014; 13(1): 36-9.

5. Galkowska H, Wojewodzka U, Olszewski WL. Chemokines, cytokines, and growth factors in keratinocytes and dermal endothelial cells in the margin ofchronic diabetic foot ulcers. Wound Repair Regen. 2006; 14(5): 558-65.

6. Maruyama K, Asai J, Ii M, Thorne T, Losordo DW, D'Amore PA. Decreased macrophage number and activation lead to reduced lymphatic vessel formation and contribute to impaired diabetic wound healing. Am J Pathol. 2007; 170 (4): 1178-91.

7. Galiano RD, Tepper OM, Pelo CR, Bhatt KA, Callaghan M, Bastidas N, Bunting S, Steinmetz HG, Gurtner GC. Topical vascular endothelial growth factor accelerates diabetic wound healing through increased angiogenesis and by mobilizing and recruiting bone marrow derived cells. Am J Pathol. 2004; 164(6): 1935-47.

8. Singh VP, Bali A, Singh N, Jaggi AS. Advanced Glycation End Products and Diabetic Complications. Korean J Physiol Pharmacol. 2014;18(1):1-14.

9. Keast DH, Fraser C. Treatment of chronic skin ulcers in individuals with anemia of chronic disease using recombinant human erythropoietin (EPO): a review of four cases. Ostomy Wound Manage. 2004; 50(10): 64-70.

10. Bhattacharya S, Mishra, R K. Pressure ulcers: Current understanding and newer modalities of treatment. Indian $\mathrm{J}$ Plast Surg. 2015; 48(1): 4-16

11. Özler GS, Okuyucu S, Akoğlu E. The Efficacy of Sucralfate and Chlorhexidine as an Oral Rinse in Patients with Recurrent Aphthous Stomatitis. Advances in Medicine. 2014;2014: Article ID 986203. 
12. Abbasi F, Raoof M, Khatami R, Shadman N, BorjianBoroojeni F, Nazari F. Effectiveness of Amlexanox and Adcortyl for the treatment of recurrent aphthous ulcers. Journal of Clinical and Experimental Dentistry. 2016;8(4):e368-e372.

13. Chandak R, Sonule S, Chandak M, Rawlani S, Gaikwad R. Efficacy of single application of topical doxycycline hyclate and triamcinolone acetonide in denture adhesive in the management of recurrent aphthous stomatitis: A comparative study. J Oral Res Rev 2017;9:72-6.

14. Femiano F, Buonaiuto C, Gombos F, Lanza A, Cirillo $\mathrm{N}$ : Pilot study on recurrent aphthous stomatitis (RAS): a randomized placebo- controlled trial for the comparative therapeutic effects of systemic prednisone and systemic montelukast in subjects unresponsive to topical therapy. Oral Surg Oral Med Oral Pathol Oral Radiol Endod. 2010; 109: 402-7.

15. Elad S, Epstein JB, von Bültzingslöwen I, Drucker S, Tzach $\mathrm{R}$, Yarom N. Topical immunomodulators for management of oral mucosal conditions, a systematic review; Part II: miscellaneous agents. Expert Opin Emerg Drugs. 2011; 16(1):183-202.

16. Misra M, Aiman U. Alloxan: An unpredictable drug for diabetes induction? Indian J Pharmacol. 2012;44(4): 538- 9 .

17. Gomez, R, Huber J, Tombini G, Barros HMT. Acute effect of different antidepressants on glycemia in diabetic and non-diabetic rats. Braz J Med Biol Res.2001;34(1)57-64.

18. Lim YS, Kwon SK, Park JH, Cho CG, Park SW, Kim WK. Enhanced mucosal healing with curcumin in animal oral ulcer model. Laryngoscope. 2016 ;126(2): 68-73.

19. Bashkar, SN, 1990. Orban's Oral Histology and Embryology: 11th Ed. Baltimore, Boston, Chikago, London, Piladephia, Sydney, Toronto: Mosby st. Louis, pp: $339-41$, 349 - 50, 365, 470-73.

20. Negrini J, Mozos, Escamilla A, Pérez J, Lucena R, Guerra $\mathrm{R}$, Ginel PJ. Effects of topical insulin on second-intention wound healing in the red-eared slider turtle (Trachemys scripta elegans) - a controlled study. BMC Vet Res. 2017; 13: 160 .

21. Zhang Z, LV L. Effect of local insulin injection on wound vascularization in patients with diabetic foot ulcer. Exp Ther Med. 2016;11(2):397-402.

22. Lima MHM, Caricilli AM, de Abreu LL, Arau' jo EP,
Pelegrinelli FF, Thirone AC, Tsukumo DM, Pessoa AF, dos Santos MF, de Moraes MA, Carvalheira JB, Velloso LA, Saad MJ. Topical Insulin Accelerates Wound Healing in Diabetes by Enhancing the AKT and ERK Pathways: A Double-Blind Placebo-Controlled Clinical Trial PLoS One. 2012; 7(5): e36974.

23. Yu T, Gao M, Yang P, Pei Q, Liu D, Wang D, Zhang X, Liu Y. Topical insulin accelerates cutaneous wound healing in insulin-resistant diabetic rats. Am J Transl Res. 2017; 9(10):4682-93.

24. El-said DM, Abd- Elmoniem A E 2, Mohamed Abd Elsalam Mohamed M Af, Ali wG. Effect of Using Topical Insulin on Improving Pressure Ulcers Healing Among Neurological Patients. IOSR-JNHS. 2017; 6 (6): 80-5.

25. Apikoglu-Rabus S, Izzettin FV, Turan P, Ercan F. Effect of topical insulin on cutaneous wound healing in rats with or without acute diabetes. Clin Exp Dermatol. 2010; 35(2):180-5.

26. Azevedo F, Pessoa A, Moreira G, Dos Santos M, Liberti E, Araujo E, Carvalho C, Saad M, Lima MH. Effect of Topical Insulin on Second-Degree Burns in Diabetic Rats. Biol Res Nurs. 2016; 18(2):181-92.

27. Praveen JRA, Kumar PN. Topical application of insulin in the diabetic wound ulcer of foot and its comparison with regular normal saline dressing. J. Evolution Med. Dent. Sci. 2017;6(95):7020-5,

28. Shanley LJ, McCaig CD, Forrester JV, Zhao M. Insulin, not leptin, promotes in vitro cell migration to heal monolayer wounds in human corneal epithelium. Invest Ophthalmol Vis Sci. 2005;45:1088-94.

29. Fai S, Ahem A, Mustapha M, Mohd Noh UK, Bastion MC. Randomized Controlled Trial of Topical Insulin for Healing Corneal Epithelial Defects Induced During Vitreoretinal Surgery in Diabetics. Asia Pac J Ophthalmol (Phila). 2017; 6(5):418-24.

30. Nzeako HC, Emegoakor CD, Chianakwana GU, Anyanwu SNC, Ezejindu DN, Ogbuanu OM. Effect Of Topical Insulin On Wound Healing InAdult Male Guinea Pigs. CIB Tech Journal of Surgery 2017; 6 (2) 1-14.

31. Chen X, Zhang X, Liu Y. Effect of topical insulin application on wound neutrophil function. Wounds. 2012;24:178-84.

32. Chen X, Liu Y, Zhang X. Topical insulin application improves healing by regulating the wound inflammatory response. Wound Repair Regen. 2012; 20(3):425-34. 
33. Rezvani O, Shabbak E, Aslani A, Bidar R, Jafari M, Safarnezhad S. A randomized, double-blind, placebo-controlled trial to determine the effects of topical insulin on wound healing. Ostomy Wound Manage. 2009;55(8):22-8.

34. Zhang XJ, Chinkes DL, Sadagopa Ramanujam VM, Wolfe RR. Local injection of insulin-zinc stimulates DNA synthesis in skin donor site wound. Wound Repair Regen. 2007;15(2):258-65.
35. Ramarao K, Ramu L. Comparative Study between the Effect of Topical Insulin and Normal Saline Dressing in Healing of Diabetic Foot Ulcers. Int. J of Contem Med Res.2017;4(6):1337-9

36. Scimeca CL, Bharara M, Fisher TK, Kimbriel H, Mills JL and Armstrong DG. Novel use of insulin in continuous-installation negative pressure wound therapy as wound chemotherapy. J Diabetes Sci Technol. 2010 Jul; 4(4): 820-4. 